\title{
Curcumin Protects Metronidazole and X-ray Induced Cytotoxicity and Oxidative Stress in Male Germ Cells in Mice
}

\section{Singh S. ${ }^{1}$, Das Roy L. ${ }^{1,2}$, Giri S. ${ }^{1}$}

${ }^{1}$ Department of Life Science and Bioinformatics, Assam University, Silchar, India; 2Department of Biology, University of North Carolina at Charlotte, Charlotte, USA

Received August 9, 2012; Accepted April 8, 2013.

Key words: Metronidazole - X-ray - Lipid peroxidation - Glutathione Superoxide dismutase - Sperm head abnormality - Curcumin

Abstract: Metronidazole (MTZ) is a common antiparasitic and antibacterial drug. The drug and $X$-ray induced effects in mouse sperm count, sperm head abnormality and some oxidative stress parameters have been studied. Simultaneously the protective role of curcumin has been evaluated. MTZ, $40 \mathrm{mg} / \mathrm{kg}$ bw and $13.4 \mathrm{mg} / \mathrm{kg}$ bw $\times 3$ days exposure induced abnormal sperm head and reduced total sperm count in Swiss albino mice both after $24 \mathrm{~h}$ and 35 days of exposure. However, MTZ treatment in mice receiving X-ray irradiation ( $0.5 \mathrm{~Gy}$ ) did not changed the incidence of abnormal sperm population or decrease in the total sperm count. Hepatic glutathione (GSH), superoxide dismutase (SOD) declined significantly during the treatment phase with significant rise in lipid peroxidation of the tissue. The cellular changes were estimated by using lipid peroxidative indices like thiobarbituric acid reactive substances (TBARS). Elevated TBARS is indicative of oxidative stress in treated mice. Furthermore, curcumin pre-treatment apparently reduced the frequency of sperm head abnormality and TBARS induced by MTZ alone or in combination with X-ray and increased the levels of hepatic GSH and SOD. The additive effects of MTZ and X-ray could not be observed with regards to sperm head abnormality and total sperm count in the tested dose range although the cellular antioxidants were found to be significantly lowered and lipid peroxidantion increased. The possible role of MTZ and X-ray inducing sperm abnormality, decreased sperm count and alteration in GSH, SOD and TBARS and defensive role of curcumin have been evaluated.

Mailing Address: Prof. Sarbani Giri, PhD., Department of Life Science and Bioinformatics, Assam University, Silchar-788011, Assam, India; Phone: +91038 422708 23; e-mail: girisarbani@yahoo.com 


\section{Introduction}

Sperm morphology has been repeatedly used as indicator of toxicity and mutagenicity in mammals (Hemavathi and Rahiman, 1993; Khan and Sinha, 1996; Bustos-Obregón and González-Hormázabal, 2003; Joshi et al., 2003). The SHA assay is a sensitive and reliable parameter and is widely used to identify germ cell mutagens (Wyrobek and Bruce, 1978; Giri et al., 2002a, b; el-Nahas and el-Ashmawy, 2004). It is an inexpensive and convenient method. MTZ, (1-[2-hydroxyethyl]-2-methyl-5-nitroimidazole), an antiparasitic and antibacterial compound, is one of the world's most used drugs and 100 most prescribed drugs in the US (www.rxlist.com). It is one of the 10 most used drugs during pregnancy (Thapa et al., 1998). The drug can induce alterations in somatic and germinal cells (Grover et al., 2001). It has been reported that after 6 weeks of treatment of rats with MTZ (400 mg/kg/day), decreases testicular weight, testicular and epididymal spermatozoon counts and causes abnormal spermatozoon morphology with degeneration of seminiferous tubules (Grover et al., 2001). Abnormalities in the flagellum and the head as well as decrease in the number of motile spermatozoon have been reported in the morphological analysis after MTZ treatment (el-Nahas and el-Ashmawy, 2004; Mudry et al., 2007). Depleted serum testosterone level in MTZ treated mice (Karbalay-Doust and Noorafshan, 2011) has also been reported.

Likewise, studies on rodents have demonstrated that high doses of radiation can severely damage spermatogonial stem cells (Meistrich, 1982) and increase the frequency of translocations in spermatocytes (Pomerantseva et al., 1997). Radiation may also have an indirect negative effect on sperm DNA via the production of an excess of reactive oxygen species (ROS). The high radiosensitivity of spermatogonial cells makes the mouse testis an effective in vivo model to study the biological effects of low doses radiation (Rao et al., 1991). A variety of gross sperm head abnormalities result from exposure of mouse testis to low doses of X-rays (Wyrobek, 1979). Curcumin, a naturally occurring phenolic compound and an important component of many eastern diets derived from turmeric (Curcuma longa, Zingiberaceae) has been known since ancient times to possess therapeutic properties. It has been reported to scavenge oxygen free radicals and to inhibit lipid peroxidation and protect the cellular macromolecules, including DNA from oxidative damage (Kalpana and Menon, 2004; Barzegar and Moosavi-Movahedi, 2011; Singh et al., 2011). The radioprotective effect of curcumin has been evaluated by Srinivasan et al. (2006) taking lipid peroxidation, glutathion, superoxide dismutase, catalase etc. as endpoints. However, there are some reports which indicate the pro-oxidative as well as carcinogenic activities of curcumin under certain condition (López-Lázaro, 2008; Dance-Barnes et al., 2009). The extensive use of curcumin as natural antioxidants supported by several independent research data in favour of curcumin as antioxidant lead us to evaluate antioxidant properties. No work has been carried out in MTZ treated mice with X-ray exposure taking sperm anomalies into account. Since MTZ is an extensively used drug, it is common 
that people working in radiological units of hospitals and diagnostic centers get exposed to X-ray and MTZ in combination. Therefore, in the present study, an attempt has been made to analyze the drug mutagen interaction on germinal cells of male mice and protective role of natural antioxidant curcumin has been evaluated.

\section{Material and Methods}

Test chemicals

Metronidazole (1-[2-hydroxyethyl]-2-methyl-5-nitroimidazole); (CAS Registry No. 443-48-1) manufactured by J. B. Chemicals and Pharmaceutical Ltd., India. Mitomycin C (MMC) was obtained from Cadila Pharmaceutical, India. Eosin $Y$ was obtained from HiMedia Laboratories, Mumbai, India. Trichloroacetic acid (Batch No. 451096), Titan Biotech Limited; 2-Thiobarbituric acid (CAS No. 504-17-6), HiMedia Laboratories. Tris HCl, EDTA, Pyrogallol, DTNB purchased from Sisco Research Laboratories Pvt. Ltd. (Mumbai, India), curcumin (CAS No. 458-37-7) bought from Sigma Chemicals.

\section{Animals and dose}

The study has required clearance from Institutional Animal Ethics Committee. Swiss albino male mice, in the age group of 10-12 weeks and weighing 20-25 g purchased from Pasture Institute, Shillong, India. The animals were maintained in laboratory conditions at a room temperature of $25 \pm 5^{\circ} \mathrm{C}$ and in $12 \mathrm{~h}$ dark and $12 \mathrm{~h}$ light cycles. Food pellets and water were provided ad libitum. One single dose $(40 \mathrm{mg} / \mathrm{kg} \mathrm{bw})$ and one chronic dose $(13.4 \mathrm{mg} / \mathrm{kg}$ bw $\times 3$ days $)$ given intraperitoneally were tested for occurrence of sperm head abnormality and other biochemical parameters. Mitomycin C (2 mg/kg bw) was used as positive control and the negative control mice were given equal volumes of normal saline. For irradiation study, the instrument used for X-ray was Diagnox-60 (Meditronic) with absorption dose of $0.5 \mathrm{~Gy}$. Instrument was operated at room temperature. Irradiation was given 30 min after both the acute and chronic dose of MTZ treatment. $8 \mathrm{mg} / \mathrm{kg}$ bw of curcumin was given intraperitoneally for five days before MTZ and X-ray exposure. Sample size was three mice for each treatment group and 3,000 cells were studied in each animal.

\section{Sperm head assay}

Male mice (8-10 weeks) were treated with the same concentrations intraperitoneally as above for $24 \mathrm{~h}$ and 35 days. The animals were sacrificed by cervical dislocation after expiry of $24 \mathrm{~h}$ and 35 days of the last treatment. Both the cauda epididymis were dissected out and placed in normal saline. The sperms were released by mechanical disruption and washing of the epididymis. A drop of suspension was taken and smear was made, air dried and fixed in methanol for 10 min. 1,000 sperms were scored and the abnormalities were categorized as close 
as described by Wyrobek and Bruce (1978). Moreover, the suspension described above was used for total sperm count.

Biochemical assays

After sacrificing mice, liver was removed, weigh and cleaned. Tissue homogenate $(10 \%)$ was prepared in ice cold normal saline and centrifuged for $10 \mathrm{~min}$ at 3,000 rpm. The supernatant was used for performing biochemical tests. All biochemical assays were performed with a Thermo Scientific (Genesys 20) Spectrophotometer. Lipid peroxidation was assayed by the method of Safiq-Ur-Rehman (1984). GSH content was determined by estimating free $-\mathrm{SH}$ groups using 5,5'-dithiobis-2-nitrobenzoic (DTNB) acid method of Sedlak and Lindsay (1968). SOD activity was measured by the procedure of Marklund and Marklund (1974).

\section{Statistical analysis}

Quantitative data were expressed as mean $\pm \mathrm{SE}$ and analyzed by one way analysis of variances (ANOVA) followed by Tukey's multiple comparison test for pair wise comparison between study groups. Student's $t$-test was used to determine the significance of cellular parameters using GraphPad Prism Software. Differences were considered statistically significant when $\mathrm{P}<0.05$.

\section{Results}

Table 1 and Figure 1 indicate the incidence of abnormal sperm and total sperm count of MTZ and X-ray alone and in combination. Both the acute and chronic dose of MTZ induce statistically significant increase in SHA $(P<0.001)$ after $24 \mathrm{~h}$ and 35 days of treatment when compared to control. Aberrant head morphology like amorphous, beaked, hooked, hook less, altered head, triangular, banana, pin-headed, double-headed etc. were observed. The amorphous form was found to be the most frequent type of abnormality over all the other types in both the treatment groups. When MTZ treated mice were exposed to X-ray, the incidence of abnormal sperm was not significantly changed. This indicates that X-ray in the tested dose range do not show any increase in SHA in MTZ treated mice. However, although not statistically significant, SHA in acute dose of MTZ was more than chronic dose. In all the above treatment groups a decrease in total sperm count was observed though it was not statistically significant.

MTZ as well as $X$-ray induced lipid peroxidation. In Table 2 and Figure 2A, significant increase in TBARS level after $X$-ray $(P<0.01)$, MTZ1 $(P<0.001)$ and MTZ2 $(P<0.05)$ as compared to control group has been reported. On the other hand the antioxidant enzymes GSH after MTZ2 $(P<0.05)$ and SOD levels after MTZ1 $(P<0.001)$, MTZ2 $(P<0.05)$ and $X$-ray $(P<0.05)$ were significantly depleted (Table 2, Figure $2 \mathrm{~B}$ and $\mathrm{C}$ ). Curcumin pre-treatment could ablate these effects by restoring the GSH and SOD level and reducing the TBARS level significantly (Table 2, Figure 2B and C). 
96) Prague Medical Report / Vol. 114 (2013) No. 2, p. 92-102

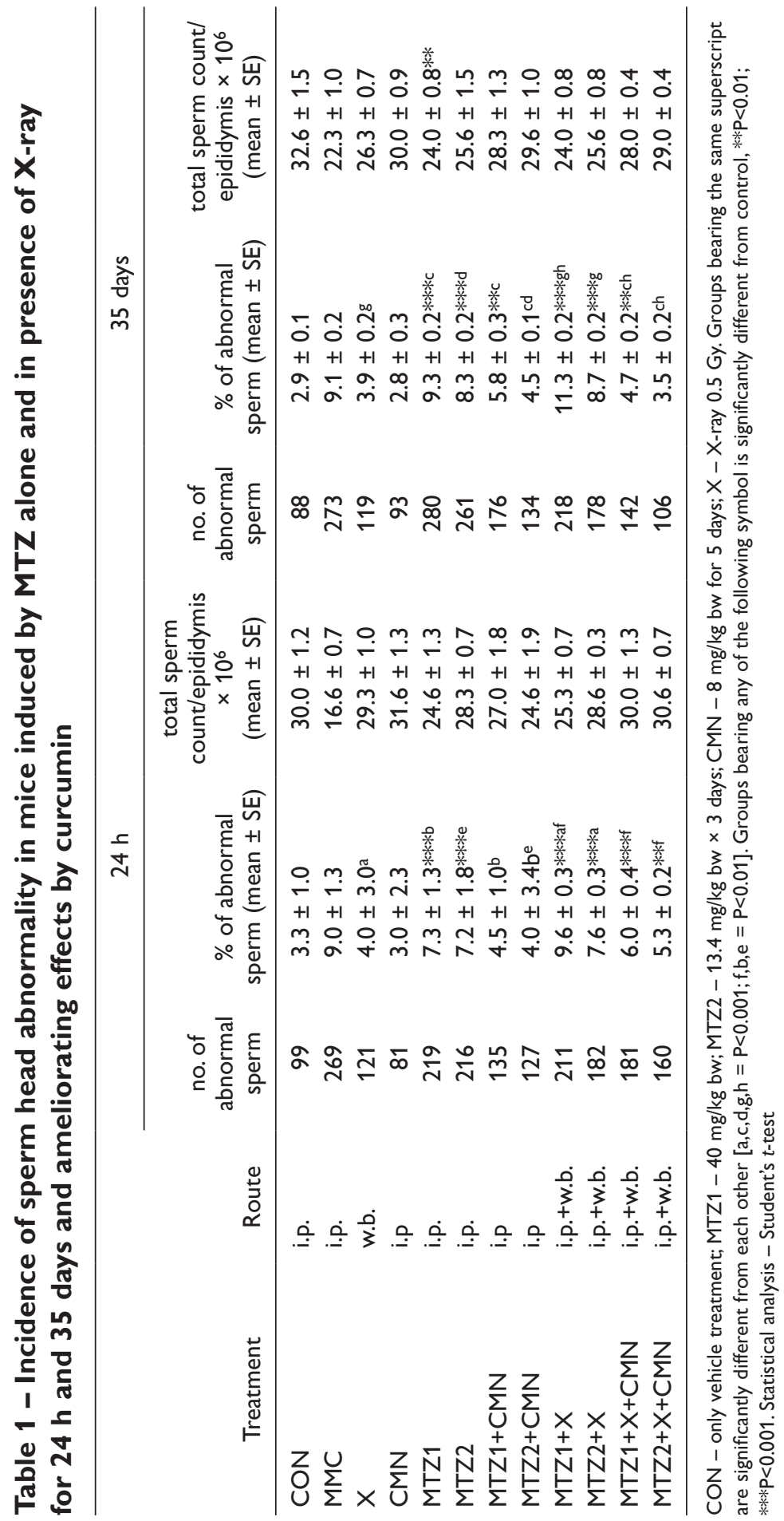

Singh S.; Das Roy L.; Giri S. 


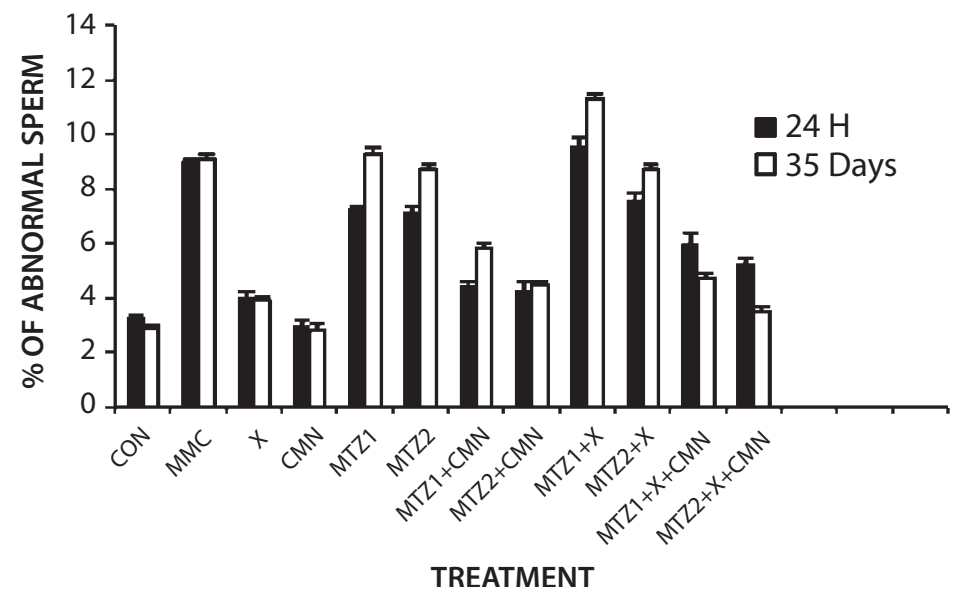

Figure 1 - Incidence of sperm head abnormality in MTZ and X-ray exposed mice and protective role of curcumin after $24 \mathrm{~h}$ and 35 days.

Values are mean $\pm \mathrm{SE} ; \mathrm{CON}$ - only normal saline treatment; MTZ1 - $40 \mathrm{mg} / \mathrm{kg}$ bw; MTZ2 - $13.4 \mathrm{mg} / \mathrm{kg}$ bw $\times 3$ days; $C M N-8$ mg/kg bw for 5 days; $X-X$-ray 0.5 Gy; MMC - mitomycin C; statistical analysis Student's t-test.

Table 2 - Oxidative stress-related indices in mice liver exposed to MTZ alone and in combination with low dose $\mathrm{X}$-ray for $\mathbf{2 4} \mathrm{h}$ and protection by curcumin

\begin{tabular}{lccc}
\hline Group/dose & $\begin{array}{c}\text { Lipid peroxidation } \\
\text { (nmol MDA/gm wet } \\
\text { tissue) }\end{array}$ & $\begin{array}{c}\text { Reduced glutathione } \\
\text { (mmol/gm wet tissue) }\end{array}$ & $\begin{array}{c}\text { Superoxide dismutase } \\
\text { (unit) }\end{array}$ \\
\hline CON & $3.5 \pm 1.1$ & $0.009 \pm 0.0005$ & $8.0 \pm 0.3$ \\
MMC & $29.6 \pm 2.0$ & $0.003 \pm 0.002$ & $0.5 \pm 0.2$ \\
CMN & $5.0 \pm 0.5$ & $0.008 \pm 0.0005$ & $6.0 \pm 0.5$ \\
X & $10.29 \pm 0.3^{* *}$ & $0.005 \pm 0.001$ & $3.2 \pm 0.5^{*}$ \\
MTZ1 & $14.3 \pm 1.2^{* * * a c}$ & $0.003 \pm 0.0005^{* * *}$ & $2.0 \pm 0.2^{* * * b}$ \\
MTZ2 & $9.0 \pm 1.2^{*}$ & $0.004 \pm 0.0003^{*}$ & $3.0 \pm 1.6^{*}$ \\
MTZ1+CMN & $9.0 \pm 1.1^{* a}$ & $0.008 \pm 0.0003$ & $5.0 \pm 0.3^{*}$ \\
MTZ2+CMN & $8.1 \pm 1.1^{\text {ac }}$ & $0.007 \pm 0.004$ & $6.0 \pm 0.7$ \\
MTZ1+X & $13.0 \pm 0.8^{* * *}$ & $0.005 \pm 0.003^{*}$ & $3.8 \pm 0.2^{*}$ \\
MTZ2+X & $8.9 \pm 0.6^{*}$ & $0.004 \pm 0.003$ & $5.0 \pm 0.3^{*}$ \\
MTZ1+X+CMN & $6.0 \pm 0.9$ & $0.006 \pm 0.0005$ & $5.1 \pm 0.3$ \\
MTZ2+X+CMN & $5.2 \pm 0.2$ & $0.007 \pm 0.001$ & $6.3 \pm 0.7^{\mathrm{b}}$ \\
\hline
\end{tabular}

Values are mean $\pm \mathrm{SE}$; CON - only normal saline treatment; MTZ1 - $40 \mathrm{mg} / \mathrm{kg}$ bw; MTZ2 - $13.4 \mathrm{mg} / \mathrm{kg}$ bw $\times 3$ days; CMN $-8 \mathrm{mg} / \mathrm{kg}$ bw for 5 days; $X$ - X-ray 0.5 Gy; MMC - mitomycin C; statistical analysis - Student's $t$-test; MDA - malonaldehyde; GSH - glutathion; SOD - superoxide dismutase. Groups bearing the same superscript are significantly different from each other $[a, b=P<0.05 ; c=P<0.001]$. Groups bearing any of the following symbol is significantly different from control, $* \mathrm{P}<0.05$; ${ }^{*} \mathrm{P}<0.01$; $* * * \mathrm{P}<0.001$ 


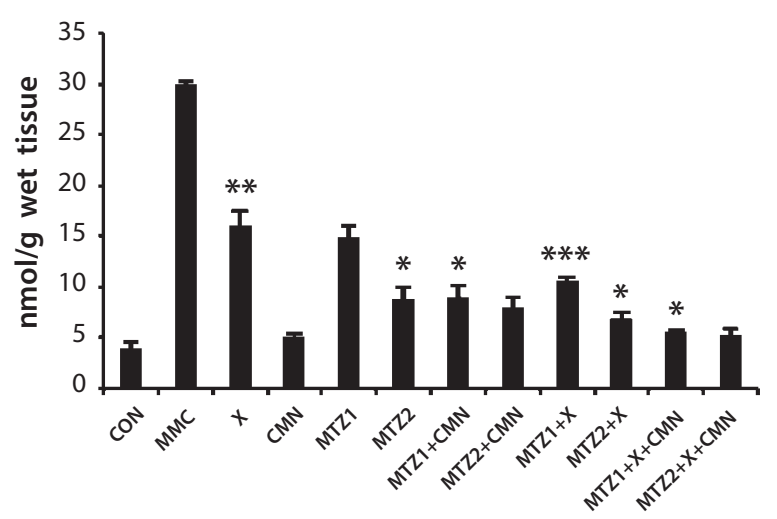

A

Treatment

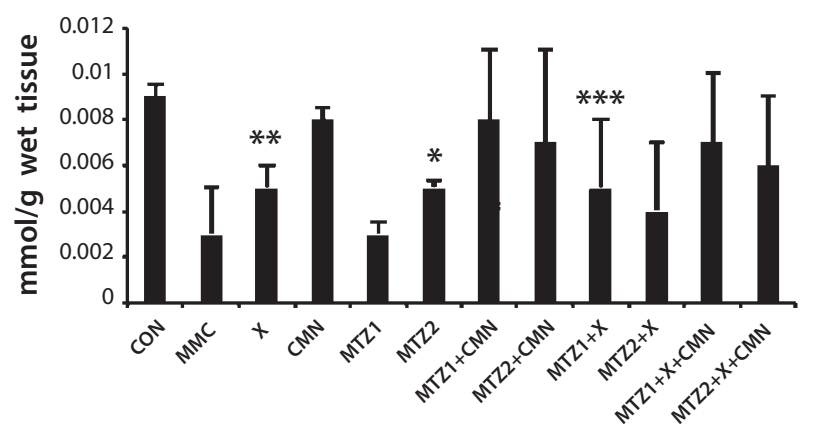

\section{Treatment}

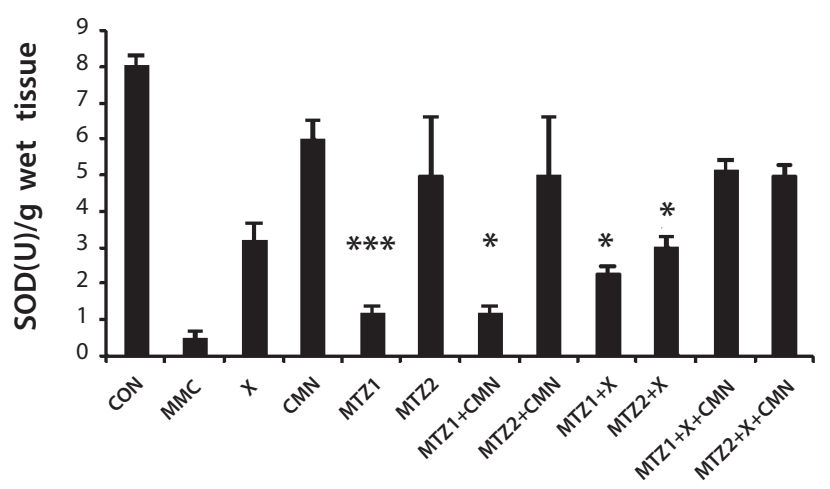

C

\section{Treatment}

Figure 2 - Role of curcumin in MTZ alone and in combination with X-ray induced hepatic: A) TBARS, B) GSH levels, C) SOD levels in mice.

Values are mean \pm SE; CON - only normal saline treatment; MTZ1 - $40 \mathrm{mg} / \mathrm{kg}$ bw; MTZ2 - $13.4 \mathrm{mg} / \mathrm{kg}$ bw $\times 3$ days; $C M N-8 \mathrm{mg} / \mathrm{kg}$ bw for 5 days; $X-X$-ray 0.5 Gy; MMC - mitomycin C; statistical analysis Student's t-test. Groups bearing any of the following symbol is significantly different from control, $* P<0.05$; $* * P<0.01$; ***P $<0.001$. 


\section{Discussion}

Since patients or hospital workers in the radiological diagnosis section undergoing MTZ medications may get exposed to low dose of $X$-ray, the interaction between drug and mutagen in inducing genotoxicity is important. In addition, the efficacy of curcumin in reducing MTZ and X-ray induced genotoxic potential was evaluated as it is a very common constituent of diet. Significant reduction in sperm count was observed in MTZ in both acute and chronic dose (Table 1). This observation is in accordance with other reports of cytotoxic effects of MTZ on total sperm count and SHA (Karbalay-Doust and Noorafshan, 2011). We also found that the acute and chronic dose of MTZ showed significant increase in the sperm head abnormality after $24 \mathrm{~h}$ of treatment (Table 1). The incidence of increased abnormal sperm head morphology after $24 \mathrm{~h}$ of exposure may not be attributed to genotoxic effect. The reason may be effect of MTZ on cell membrane components thus resulting in abnormal head morphology at maturation stage. Germ cells take about 35 days to get differentiated into functional sperm. This is the minimum time required to visualize the DNA damage which might have taken place during the development of the spermatogonial cells. However, significant increase $(P<0.001)$ in the frequency of SHA observed in the groups receiving the acute as well as chronic dose for 35 days of the treatment strongly indicate genetic alterations in the sperm DNA which might have taken place during the spermatogenesis. The exogenous substances upon getting accumulated in germ cell pool, induce alterations in sperm morphology mainly by point mutations (Chauhan et al., 2000), small alterations in testicular DNA (Topham, 1980), structural abnormality in Y-chromosome (Styrna et al., 1991), or interference of the test substance with the genetically controlled differentiation of the sperm cells (Bruce et al., 1974; Padmalatha Rai and Vijaylaxmi, 2001). The significant increase in the sperm head abnormality (Table 1) induced by MTZ indicates its probable potential as a germ cell mutagen. In a similar study with the drug chloroquine and low dose gamma radiation ( $0.5 \mathrm{~Gy}$ ) on germ cells (Das Roy et al., 2008), the incidence of SHA increased. However, same dose of X-ray did not induce any SHA in mouse test system in the present study. It was observed by Rao et al. (1991) that chronic irradiation of the testis with gamma rays is more effective in producing SHA than acute exposure with X-rays. Although the effect of radiation such as gamma rays, alpha rays and soft $\mathrm{X}$-rays may be different because that depend not only on the nature and energy of radiation but also on the biokinetics and distribution of radionuclides in the tissue both at macroscopic and subcellular level (Rao et al., 1991). Curcumin could lower the MTZ induced SHA and increase total sperm count (Karbalay-Doust and Noorafshan, 2011) (Table 1). However, the study by Burgos-Morón et al. (2010) indicate that bioavailability of curcumin is very low outside the Gl tract when administered orally limiting its antixidative potential. In our study curcumin was given intraperitoneally and the antioxidative property was achieved. Curcumin lowered the toxic effects and decreased SHA both for $24 \mathrm{~h}$ and 35 days in MTZ as well as in combination 
with X-ray significantly. Therefore, a further study is necessary to evaluate the antioxidative properties of curcumin administering through different route and evaluating the bioavaility.

Increased levels of TBARS in MTZ alone and X-ray treated mice liver tissue were detected. This may be due to the attack of free radicals on the fatty acid component of membrane lipids (Rajendra Prasad et al., 2005). The antioxidant enzymes like GSH and SOD plays important role in ROS scavenging (Turner et al., 2002). In this study, we have observed a significant decrease in the activities of SOD and GSH in MTZ treated mice liver tissue. The decrease might be due to radiation induced production of free radicals which in turn can impair the antioxidant defence mechanism leading to an increased membrane lipid peroxidation (Bhatia and Jain, 2004; Sehgal et al., 2012). The decreased GSH levels may be due to their utilization by the enhanced production of ROS (Suryanarayana et al., 2007; Balamurugan et al., 2009). After $24 \mathrm{~h}$ of treatment with X-ray depletion in GSH and SOD levels were also observed. All organisms have their own cellular defense system composed of both enzymatic as well as non-enzymatic components. Since GSH is utilized for detoxification of free radicals, increased sensitivity to oxidative stress also occurs when cells are depleted of GSH (Chen et al., 1997; Kaur and Meena, 2012; Sehgal et al., 2012). Curcumin has been found to show promising increase in superoxide dismutase activity with comparable free radical scavenging ability and an improved antioxidant efficacy (Barik et al., 2005; Girish and Pradhan, 2012; Kaur and Meena, 2012; Sehgal et al., 2012). Curcumin thus is a potent dietary antioxidant against ROS and ROS induced cellular damage (Singh and Giri, 2012).

Therefore, in the light of the findings of the present study and those reported earlier, it can be concluded that MTZ has the potential to induce genotoxicity in mammalian cells. Further, germ line cells may be relatively more sensitive. However, no synergistic effect was observed in MTZ and X-ray induced SHA and total sperm count in the tested dose range. It is advisable for patients or hospital workers under MTZ medications to avoid low dose X-ray exposures for therapeutic purpose or occupational exposure, since MTZ and X-ray are observed to cause sperm abnormality after 35 days of treatment.

Acknowledgements: The authors thank to Principal, Silchar Medical College, for allowing us to use the radiation facility. The financial support by DST-FIST to Department of Life Science and Bioinformatics and fellowship to SS from UGC is thankfully acknowledged.

\section{References}

Balamurugan, A. N., Akhov, L., Selvaraj, G., Pugazhenthi, S. (2009) Induction of antioxidant enzymes by curcumin and its analogues in human islets: implications in transplantation. Pancreas 38(4), 454-460.

Barik, A., Mishra, B., Shen, L., Mohan, H., Kadam, R. M., Dutta, S., Zhang, H. Y., Priyadarsini, K. I. (2005)

Evaluation of a new copper(II)-curcumin complex as superoxide dismutase mimic and its free radical reactions. Free Radic. Biol. Med. 39(6), 811-822.

Singh S.; Das Roy L.; Giri S. 
Barzegar, A., Moosavi-Movahedi, A. A. (2011) Intracellular ROS protection efficiency and free radicalscavenging activity of curcumin. PLoS One 6(10), e26012.

Bhatia, A. L., Jain, M. (2004) Spinacia oleracea L. protects against gamma radiations: a study on glutathione and lipid peroxidation in mouse liver. Phytomedicine 11, 607-615.

Bruce, W. R., Furrer, R., Wyrobek, A. J. (1974) Abnormalities in the shape of murine sperm after acute testicular X-irradiation. Mutat Res. 23, 381-306.

Burgos-Morón, E., Calderón-Montaño, J. M., Salvador, J., Robles, A., López-Lázaro, M. (2010) The dark side of curcumin. Int. J. Cancer 126, 1771-1775.

Bustos-Obregón, E., González-Hormázabal, P. (2003) Mice testicular damage elicited by Malathion. Int. J. Morphol. 21, 155-159.

Chauhan, L. K. S., Pant, N., Gupta, S. K. Srivastava, S. P. (2000) Induction of chromosome aberrations, micronucleus formation and sperm abnormalities in mouse following carbofuran exposure. Mutat. Res. 465, 123-129.

Chen, Z., Mutoh, M., Sumizawa, T., Furukawa, T., Haraguchi, M., Tani, A., Akiyama, S. (1997) Reversal of heavy metal resistance in multi drug resistant human KB carcinoma cells. Biochem. Biophys. Res. Commun. 236, 586-590.

Dance-Barnes, S. T., Kock, N. D., Moore, J. E., Lin, E. Y., Mosley, L. J., D’Agostino, R. B. Jr., McCoy, T. P., Townsend, A. J., Miller, M. S. (2009) Lung tumor promotion by curcumin. Carcinogenesis 30, 1016-1023.

Das Roy, L., Mazumdar, M., Giri, S. (2008) Effects of low dose radiation and vitamin C treatment on chloroquine-induced genotoxicity in mice. Environ. Mol. Mutagen. 49, 488-495.

el-Nahas, A. F., el-Ashmawy, I. M. (2004) Reproductive and cytogenetic toxicity of metronidazole in male mice. Basic Clin. Pharmacol. Toxicol. 94, 226-231.

Giri, S., Giri, A., Sharma, G. D., Prasad, S. B. (2002a) Mutagenic effects of carbosulfan, a carbamate pesticide. Mutat. Res. 519, 75-82.

Giri, S., Prasad, S. B., Giri, A., Sharma, G. D. (2002b) Genotoxic effects of malathion: An organophosphorus insecticide, using three mammalian bioassays in vivo. Mutat. Res. 514, $223-231$.

Girish, C., Pradhan, S. C. (2012) Hepatoprotective activities of picroliv, curcumin, and ellagic acid compared to silymarin on carbon-tetrachloride-induced liver toxicity in mice. J. Pharmacol. Pharmacother. 3(2), 149-155.

Grover, J. K., Vats, V., Srinivas, M., Das, S. N., Jha, P., Gupta, D. K., Mitra, D. K. (2001) Effect of metronidazole on spermatogenesis and FSH, LH and testosterone levels of pre-pubertal rats. Indian J. Exp. Biol. 39, 1160-1162.

Hemavathi, E., Rahiman, M. A. (1993) Toxicological effects of ziram, thiram and diethane M-45 assed by sperm shape abnormalities in mice. J. Toxicol. Environ. Health 38, 393-398.

Joshi, S. C., Mathur, R., Gajraj, A., Sharma, T. (2003) Influence of methyl parathion on reproductive parameters in male rats. Environ. Toxicol. Pharmacol. 14, 91-98.

Kalpana, C., Menon, V. P. (2004) Curcumin ameliorates oxidative stress during nicotine-induced lung toxicity in Wistar rats. Ital. J. Biochem. 53(2), 82-86.

Karbalay-Doust, S., Noorafshan, A. (2011) Ameliorative effects of curcumin on the spermatozoon tail length, count, motility and testosterone serum level in metronidazole-treated mice. Prague Med. Rep. 112(4), 288-297.

Kaur, G., Meena, C. (2012) Amelioration of obesity, glucose intolerance, and oxidative stress in high-fat diet and low-dose streptozotocin-induced diabetic rats by combination consisting of "curcumin with piperine and quercetin”. ISRN Pharmacol., doi:10.5402/2012/957283.

Khan, P. K., Sinha, S. P. (1996) Ameliorating effect of vitamin C on murine sperm toxicity induced by three pesticides (endosulfan, phosphamidon and mancozeb). Mutagenesis 11, 33-36.

López-Lázaro, M. (2008) Anticancer and carcinogenic properties of curcumin: considerations for its clinical development as a cancer chemopreventive and chemotherapeutic agent. Mol. Nutr. Food Res. 52 , S103-S127. 
Marklund, S., Marklund, G. (1974) Involvement of the superoxide anion radical in autooxidation of pyrogallol and a convenient assay for superoxide dismutase. Eur. J. Biochem. 47, 469-474.

Meistrich, M. L. (1982) Quantitative correlation between testicular stem cell survival, sperm production, and fertility in the mouse after treatment with different cytotoxic agents. J. Androl. 3, 58-68.

Mudry, M. D., Palermo, A. M., Merani, M. S., Carballo, M. A. (2007) Metronidazole-induced alterations in murine spermatozoa morphology. Reprod. Toxicol. 23, 246-252.

Padmalatha Rai, S., Vijayalaxmi, K. K. (2001) Tamoxifen citrate induced sperm shape abnormality in the in vivo mouse. Mutat. Res. 492,1-6.

Pomerantseva, M. D., Ramaiya, L. K., Chekhovich, A. V. (1997) Genetic disorders in house mouse germ cells after the Chernobyl catastrophe. Mutat. Res. 381, 97-103.

Rajendra Prasad, N., Menon, V. P., Vasudev, V., Pugalendi, K. V. (2005) Radioprotective effect of sesamol on $\gamma$-radiation induced DNA damage, lipid peroxidation and antioxidants level in cultured human lymphocytes. Toxicology 209, 225-335.

Rao, D. V., Narra, V. R., Howell, R. W., Lanka, V. K., Sastry, K. S. (1991) Induction of sperm head abnormalities by incorporated radionuclides: Dependence on subcellular distribution, type of radiation, dose rate, and presence of radioprotectors. Radiat. Res. 125, 89-97.

Sedlak, J., Lindsay, R. H. (1968) Estimation of total protein-bound and nonprotein sulfhydryl groups in tissues with Ellman's reagent. Anal. Biochem. 24(25), 192-205.

Sehgal, A., Kumar, M., Jain, M., Dhawan, D. K. (2012) Synergistic effects of piperine and curcumin in modulating benzo(a)pyrene induced redox imbalance in mice lungs. Toxicol. Mech. Methods 22(1), 74-80.

Shafiq-Ur-Rehman (1984) Lead induced regional lipid peroxidation in brain. Toxicol. Lett. 21, 333-337.

Singh, S., Giri, S. (2012) Review on curcumin and genome stability. Assam Univ. J. Sci. Technol.: Biol. Environ. Sci. 9(1), 151-156.

Singh, U., Barik, A., Singh, B. G., Priyadarsini, K. I. (2011) Reactions of reactive oxygen species (ROS) with curcumin analogues: structure-activity relationship. Free Radic. Res. 45(3), 317-325.

Srinivasan, M., Rajendra Prasad, N., Menon, V. P. (2006) Protective effect of curcumin on gamma-radiation induced DNA damage and lipid peroxidation in cultured human lymphocytes. Mutat. Res. 611, 96-103.

Styrna, J., Imai, H. T., Moriwaki, K. (1991) An increased level of sperm abnormalities in mice with a partial deletion of the $Y$ chromosome. Genet. Res. 57, 195-199.

Suryanarayana, P., Satyanarayana, A., Balakrishna, N., Kumar, P. U., Reddy, G. B. (2007) Effect of turmeric and curcumin on oxidative stress and antioxidant enzymes in streptozotocin-induced diabetic rat. Med. Sci. Monit. 12, 286-292.

Thapa, P. B., Whitlock, J. A., Brockman Worrell, K. G., Gideon, P., Mitchel, E. F. Jr., Roberson, P., Pais, R., Ray, W. A. (1998) Prenatal exposure to metronidazole and risk of childhood cancer: a retrospective cohort study of children younger than 5 years. Cancer 83, 1461-1468.

Topham, J. C. (1980) Chemically induced transmissible abnormalities in sperm head shape. Mutat. Res. 70, 109-114.

Turner, N. D., Braby, L. A., Ford, J., Lupton, J. R. (2002) Opportunities for nutritional amelioration of radiationinduced cellular damage. Nutrition 18, 904-912.

Wyrobek, A. J. (1979) Changes in mammalian sperm morphology after X-ray and chemical exposure. Genetics 92, S105-S119.

Wyrobek, A. J., Bruce, W. R. (1978) Induction of sperm-shape abnormalities in mice and humans. In: Chemical Mutagens: Principles and Methods for Their Detection. Hollaender, A., Editor, Plenum Press, New York. 